\title{
Agroindústria, industrialização e competitividade: uma análise do complexo agroindustrial do Rêconcavo Sul da Bahia
}

\author{
Agroindustry, industrialization and competitiveness: an analysis of the \\ agribusiness complex of the Southern Rhonecavavo of Bahia
}

\section{Agroindustria, industrialización y competitividad: un análisis del complejo de agresividad del Rhonecavavo Sur de Bahia}

\section{Resumo}

O objetivo deste estudo foi analisar como o processo de industrialização, ocorrido no Estado da Bahia - iniciado formalmente na década de 50, do século passado, com a instalação da refinaria Landulfo Alves -, influenciou as formações ou as complementações dos complexos industriais ao longo do Estado. Para o alcance do proposto, a discussão girou em torno do início do processo industrial baiano e das concepções que são utilizadas para caracterizar a produção agropecuária a partir da noção de Complexo Agroindustrial. Além disto, apresentamos uma breve análise acerca das principais características do Complexo Agroindustrial do Recôncavo Sul da Bahia.Os resultados apontam para a necessidade de um planejamento estratégico voltado para o desenvolvimento das potencialidades físicas, logísticas e intelectuais do Complexo em questão, embora ele se apresente altamente importante para a atividade avícola da Bahia.

Palavras-Chave: Complexo Agroindustrial; Cadeia produtiva;Industrialização Baiana.

\section{Abstract}

The aim of this study was to analyze how the industrialization process, which took place in the State of Bahia formally started in the 1950s with the installation of the Landulfo Alves refinery -, influenced the formation or complementation of the industrial complexes along the State.To reach the proposed, the discussion revolved around the beginning of the Bahian industrial process and the conceptions that are used to characterize the agricultural production from the notion of Agroindustrial Complex. In addition, we present a brief analysis of the main characteristics of the Recôncavo Sul da Bahia Agroindustrial Complex .The results point to the need for a

\footnotetext{
${ }^{1}$ Mestrando em Planejamento Territorial pela UEFS (Universidade Estadual de Feira de Santana).Graduado em Economia pela UEFS (Universidade Estadual de Feira de Santana). E-mail:

2 Doutor em Educação e Contemporaneidade pela Universidade do Estado da Bahia e Mestre em Gestão Integrada de Organizações pela Universidade do Estado da Bahia (UNEB); especialista em Gestão Organizacional (lato sensu) e graduado em Ciências Econômicas pela Universidade Estadual de Feira de Santana (UEFS). Atua como docente no curso de Ciências Econômicas e Engenharia Agronômica da UEFS, na PósGraduação Lato sensu em Gestão Universitária e no Programa de Pós-Graduação em Planejamento Territorial (PLANTERR)-Mestrado; Membro do Comitê de Iniciação Científica e Coordenador do Programa Incubadora de Iniciativas da Economia Popular e Solidária (IEPS), bem como líder do Grupo de Estudos e Pesquisas em Economia Popular e Solidária e Desenvolvimento Local Solidário (GEPOSDEL). E-mail:
} 
strategic planning focused on the development of the physical, logistic and intellectual potentialities of this Complex, although it is highly important for the poultry activity of Bahia.

Keywords: Agroindustrial Complex; Production chain; Bahian Industrialization.

\section{Resumen}

El objetivo de este estudio fue analizar el proceso de industrialización, ocurrido en Estado de Bahia- Iniciado formalmente en la década de 50, del siglo pasado, con la instalación de la refinería Landulfo Alves-, influenció las formaciones o las complementaciones de los complejos industriales del Estado. Para el logro del propuesto, la discusión transcurrió a partir del inicio del proceso industrial baiano y de las concepciones que son utilizadas para caracterizar la producción agropecuaria a partir de la noción de Complejo Agroindustrial. Además presentamos un breve análisis sobre las principales características del Complejo Agroindustrial del Reconcavo Sur de Bahia. Los resultados apuntan la necesidad de una planificaciónestratégicapara el desarrollo de las potencialidades físicas, logísticas e intelectuales del complejo en cuestión, aunque este sea muy importante para la actividad avícola de Bahia.

Palabras Clave: Complejo Agroindustrial; Cadena Productiva; Industrialización Baiana.

\section{INTRODUÇÃO}

O setor industrial sempre teve uma significativa presença na economia baiana, em especial, o setor da indústria de transformação (aquela que transforma matéria-prima em produto final ou intermediário para outra indústria), considerado o principal motor do crescimento e do desenvolvimento da Bahia, sobretudo a partir do início dos anos 70 coma instalação do Polo Petroquímico de Camaçari.Sua importância estende-se até o início do século XXI, período marcado pelo crescimento acelerado da economia baiana, sustentado pelo desempenho do setor industrial.

Como sublinham Cavalcantti (2008), Guerra e Teixeira (2002), a Bahia, no início dos anos 1960, começou a colocar em prática uma política de desenvolvimento industrial por meio de processo de intervenções estatais planejadas, mormente, na Região Metropolitana de Salvador (RMS), sob a oferta de terrenos infraestruturados e incentivos fiscais. Segundo Pessoti (2008), esta política foi responsável por uma média de crescimento anual de 7\% do PIB do Estado entre as décadas de 60 e 70, ancorado, principalmente, pelo Centro Industrial de Aratu e o Complexo Petroquímico de Camaçari. Para estes autores, a década de 70 pode ser entendida como um período de solidificação do processo de industrialização iniciado nos anos 50, processo este que ganha força após a implantação do Complexo Petroquímico de Camaçari (COPEC), que transformou o ambiente industrial baiano em condições mais favoráveis ao setor secundário (PESSOTI; PESSOTI, 2010). 
Com a entrada em operação do COPEC, esperava-se aumentar, de forma expressiva, a receita fiscal do Estado e do município de Camaçari. Um estudo detalhado da contribuição financeira do polo previa o crescimento da arrecadação do Imposto sobre a Circulação de Mercadoria e Serviços (ICMS) em 7\% ao ano e que o orçamento de Camaçari seria, no final da década de 70, multiplicado por dezoito. A preocupação em realizar esse estudo teve como objetivo "justificar o volume significativo de recursos que deveriam ser investidos pelo governo do estado da Bahia na construção da infraestrutura física e urbano-social da área, demonstrando aos agentes financeiros, entre os quais o BNDES, a capacidade de pagamento do estado" (GUERRA; GONZALES, 2001, p. 317).

De acordo com Guerra e Teixeira (2000), essa nova fase da industrialização baiana foi direcionada aos setores químicos devido a três motivos:

i) O estado era, na época, o maior produtor de petróleo do país e até então já possuía uma refinaria (Landulfo Alves). Dessa forma, já tinha uma base técnica para a implantação do polo petroquímico.

ii) Nos primeiros anos da década de 70,havia uma carência na produção nacional de alguns insumos básicos usados pela indústria de transformação do Centro Sul.

iii) O Governo Federal tinha entre seus objetivos, a diminuição dos desequilíbrios regionais. Dado este contexto, diversos empreendimentos foram implantados, destacando-se os realizados no COPEC. Com o passar do tempo, sua consolidação fez com que a participação relativa do setor primário no PIB Setorial Baiano diminuísse de 40 \%,em 1960, para 16,4\% em 1980. O setor secundário por sua vez, no mesmo período, quase triplica sua participação, que salta de $12 \%$ para $31,6 \%$, colocando, assim, a economia baiana numa nova posição.

Consolida-se, portanto, na Bahia, ao final da década de 70, a estrutura industrial de perfil complementar às indústrias do Centro-Sul, centrada basicamente na produção de bens intermediários, principalmente da indústria petroquímica. A essa concentração setorial une-se a concentração espacial, caracterizando fortemente o novo perfil econômico do Estado. Em decorrência das externalidades e economias de aglomeração geradas pelas indústrias e infraestrutura já instaladas na RMS, fatores como logística, serviços de apoio e manutenção e Revista do Instituto Histórico e Geográfico do Pará (IIHGP), (ISSN: 2359-0831 - online), Belém, vo 06, n. 02, p. 26-40, jul. / dez. 2019. 
proximidade com fornecedores aumentam o poder de atração desta mesma região, em especial para as indústrias dinâmicas, mais modernas e tecnologicamente mais sofisticadas, a exemplo dos ramos dos produtos químicos, plásticos, farmacêuticos e veterinários (MASCARENHAS, 2001).

É neste cenário, em que tanto o Estado nacional quanto o regional formulavam políticas de industrialização voltadas para a indústria de transformação, que a agricultura também é beneficiada com o processo de industrialização. Conforme nos diz Alencar et al (2001), nos anos 70, havia um processo de crescimento bastante pujante da demanda interna do país(aumento do processo de urbanização e das atividades industriais e do setor de serviços), promovendo condições para que os complexos agroindustriais fossem estabelecidos.Diante do exposto, discutiremos, a seguir, as principais questões e características dos complexos agroindustriais no Brasil e na Bahia.

\section{OS COMPLEXOS AGROINDUSTRIAIS NO BRASIL: FORMULAÇÕES E CARACTERÍSTICAS}

A característica central da constituição dos complexos agroindústrias é a integração da agropecuária com outros ramos industriais transformando-a em um elo de uma cadeia em que se encontram, de um lado, as indústrias que fornecem à agricultura insumos,máquinas e equipamentos (setor a montante)e, do outro, as indústrias de classificação,beneficiamento e/ou industrialização da matéria-prima agrícola bem como a sua distribuição(setor a jusante)(ALENCAR ET. AL. 2001).

Para Mueller(1982), complexo agroindustrial é aquele que é visto como parte de uma estrutura maior e conformada pelos complexos industriais de toda a economia. Neste sentido, resultaria, para fins de análise, em um "macro" complexo Agroindustrial composto por vários sistemas e cadeias industriais ou complexos particulares.

Já para Kageyama et al(1987),o complexo agroindustrial será aquele que está associado à proposta de existência de vários complexos agroindustriais, que seriam compostos de micro complexos, aqueles que resultam da passagem dos complexos rurais aos agroindustriais, e dos macro complexos, aqueles que já nasceram com a finalidade industrial.

Para Marafon(2000), estas duas concepções balizam as ideias sobre a formação de complexos agroindustriais no Brasil. A premissa inicial é a de que ocorrem relações Revista do Instituto Histórico e Geográfico do Pará (IIHGP), (ISSN: 2359-0831 - online), Belém, vo 06, n. 02, p. 26-40, jul. / dez. 2019. 
intersetoriais entre agricultura-indústria. A análise insere as relações agricultura-indústria na perspectiva da absorção de inovações tecnológicas na agricultura e, nesse contexto, o setor agrícola estaria inserido em complexos industriais balizados em seus dois extremos por setores industriais oligopolizados, tendo, a partir deste processo com a industrialização da agricultura - com suas articulações com o ramo industrial -, o estabelecimento e a formação,de modo definitivo, dos complexos agroindustriais no Brasil.

Além destas características, os complexos agroindustriais possuem a capacidade de aglomerar, no território onde estão instalados, uma rede de serviços que complementam as competências dos complexos, tais como: os serviços de assistência técnica, de pesquisa e desenvolvimento de ( $\mathrm{P} \& \mathrm{D}$ ), serviços bancários, transporte, marketing, comércio, entre outros, que podem ser melhor explorados na figura 1.

FIGURA 1 - Esquematização do sistema agroindustrial.

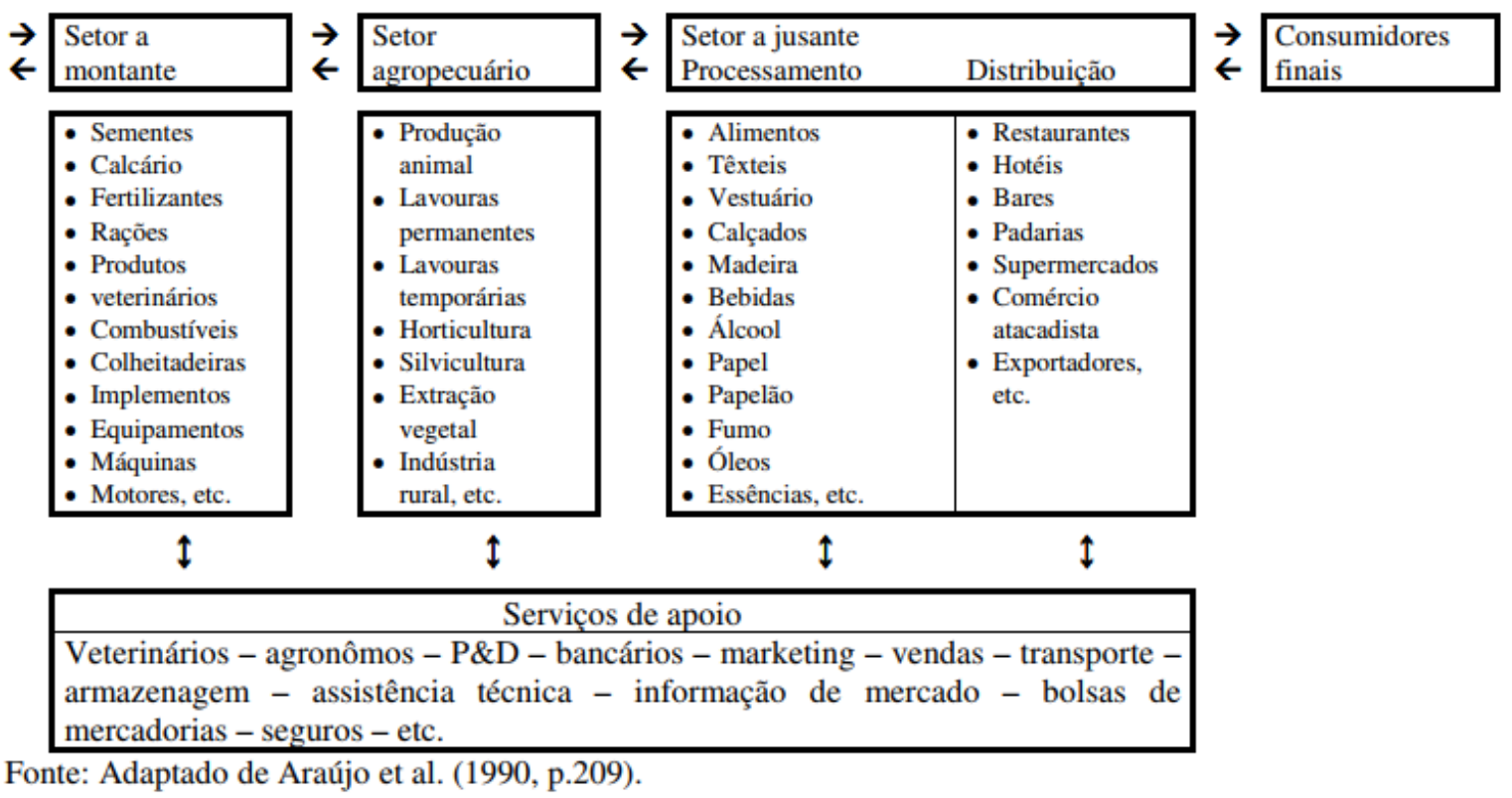

Ao constituir-se em um elo de uma cadeia para produzir,a agricultura passou a depender dos insumos que recebe das indústrias e por esta razão deixa de produzir apenas bens de consumo final, mas produz, basicamente, bens intermediários ou matérias-primas para outras indústrias (KAGEYAMA et al, 1990). Este elo se daria através do capital enquanto agente regulador da atividade econômica, o que reúne todas as atividades realizadas no complexo agroindustrial sob um único órgão regulador. 
Esta característica do complexo, para Delgado (1985) e Lamounier (1994), impede que o setor agroindustrial seja analisado como um único setor isolado, sem relações e conexões, sejam estes os setores que formam os complexos industriais, sejam os outros setores que integram a sociedade, como o próprio Estado e a sociedade internacional.

Neste novo sistema de redes, a agricultura e os agricultores são envolvidos em uma trama de interesses que inúmeras vezes são diminuídas em favor dos interesses do capital industrial ou dos grandes e médios produtores agrícolas ou, como salienta Silva (1996)

[...] os diferentes setores que formam os complexos agroindustriais, incluindo o Estado e suas agências, podem ser vistos como atores que possuem objetivos a serem atingidos e que dispõem, embora de forma diferenciada, de meios para obtê-los e se submetem a condições para a consecução dos seus objetivos. (Silva 1996, p.17)

De forma resumida, o quadro 1 apresenta uma síntese acerca das principais formulações e características do complexo industrial apresentadas até aqui balizadas nas formulações de Mueller(1982) e de Kageyama(1990). 
Quadro 1: Principais características das concepções "macro" e "micro" do complexo agroindustrial

\begin{tabular}{|c|c|c|}
\hline \multirow[t]{2}{*}{ Características } & \multicolumn{2}{|c|}{ Concepções } \\
\hline & "Macro" complexo & "Micro" complexo \\
\hline Ideia central & $\begin{array}{c}\text { Corresponde a um espaço econômico } \\
\text { determinado caracterizado através da } \\
\text { homogeneidade da base técnica. É } \\
\text { batizado pela noção de complexo } \\
\text { industrial. Apresenta sistemas ou } \\
\text { cadeias agroindustriais que se } \\
\text { caracterizam pela integração tanto a } \\
\text { montante como a jusante do setor } \\
\text { agrícola. }\end{array}$ & $\begin{array}{l}\text { Analisa as transformações do setor } \\
\text { agropecuário através da existência dos } \\
\text { Complexos Rurais e da sua } \\
\text { decomposição, dos processos de } \\
\text { modernização e industrialização da } \\
\text { agricultura até a formação dos } \\
\text { Complexos Agroindustriais. Enfatiza a } \\
\text { existência de vários Complexos } \\
\text { Agroindustriais. }\end{array}$ \\
\hline $\begin{array}{l}\text { Papel do } \\
\text { Estado }\end{array}$ & $\begin{array}{l}\text { O Estado atua como gestor do } \\
\text { processo de acumulação na } \\
\text { agricultura. }\end{array}$ & $\begin{array}{c}\text { O Estado desempenha papel } \\
\text { fundamental na construção dos CAI's e } \\
\text { no entendimento da "nova" dinâmica } \\
\text { da agricultura brasileira. }\end{array}$ \\
\hline $\begin{array}{l}\text { Setor } \\
\text { dinâmico }\end{array}$ & Indústria a montante. & Indústria a montante. \\
\hline Agricultura & $\begin{array}{c}\text { Não perde suas características em } \\
\text { função da integração com a indústria e } \\
\text { do modo industrial e empresarial da } \\
\text { condução das atividades nos } \\
\text { estabelecimentos agrícolas. }\end{array}$ & $\begin{array}{l}\text { A modernização corresponde a uma } \\
\text { etapa da industrialização da } \\
\text { agricultura e da formação dos CAI's } \\
\text { através da sua integração } \\
\text { intersetorial. }\end{array}$ \\
\hline Tipologia & Não apresenta. & $\begin{array}{c}\text { Complexos Agroindustriais completos, } \\
\text { incompletos, atividades agrícolas } \\
\text { modernizadas e artesanais. }\end{array}$ \\
\hline $\begin{array}{l}\text { Principais } \\
\text { autores }\end{array}$ & $\begin{array}{c}\text { G. Muller, R Lauschener, N. Araújo, } \\
\text { A.P. Guimarães. }\end{array}$ & A. Kageyama, J. Graziano da Silva. \\
\hline
\end{tabular}

Fonte: Marfaron (2000).

De qualquer forma, o Complexo Agroindustrial foi constituído e se expandiu através da modernização técno-econômica da agricultura brasileira, e esse processo não caracterizou apenas o "estilo", mas o próprio "modelo econômico" de desenvolvimento da agricultura brasileira, nas décadas de 70 e 80 (COSTA, 1999).

No Brasil, os complexos agroindustriais ocupam posição de destaque na economia nacional, como ressalta Gonçalves (2011), com a agropecuária ocupando uma posição bastante competitiva, tanto no mercado nacional quanto no internacional, como também o mercado de alimentos e fibras, embora estes ainda enfrentem limitações tanto de ordem externa quanto interna, ocupando, porém, posição de destaque nacional tanto em termos econômicos quanto na geração de emprego.

A seguir, discutiremos o caso do complexo agroindustrial localizado no Recôncavo Sul da Bahia, apresentando as principais características que as distinguem como um complexo 
agroindustrial e analisando suas singularidades e seu papel altamente competitivo dentro da economia baiana.

\section{O COMPLEXO AGROINDUSTRIAL DO RECÔNCAVO SUL DA BAHIA}

Antes de partirmos para a análise do complexo agroindustrial do Recôncavo Sul da Bahia, é salutar primeiro delimitar a área de estudo que é composta por 13 municipios (Cabaçeiras do Paraguaçu, Cachoeira, Conceição da Feira, Conceição do Almeida, São Félix, Cruz das Almas, Governador Mangabeira,Maragogipe, Muritiba, Santo Amaro, Sapeaçu, São Felipe e São Gonçalo dos Campos) que estão localizados em duas regiões econômicas próximas(Paraguaçu e Recôncavo Sul).

Porém, conforme nos diz Souza (2004), a atividade agroindustrial do complexo(atividade de avicultura) está localizada em apenas cinco municípios do Recôncavo Sul, a saber: Conceição da Feira, São Gonçalo, Cachoeira, Muritiba e Cruz das Almas. Este autor também atenta para o fato de que, embora fora da região de análise, é preciso destacar o município de Feira de Santana(no Portal do Sertão) por sua proximidade e influência socioeconômica nos demais municípios em foco, por concentrar empresas de produção especializada de suporte fundamental para a atividade avícola.

Cabe a ressalva de que em Feria de Santana está instalada a Avipal, a maior agroindústria avícola do Estado. Juntos, os seis municípios formam o maior polo agroindustrial avícola do Estado da Bahia, com capacidade de alojamento de 3 milhões de aves/mês(ABA, 2003).

Apresentadas as devidas localizações, passemos a analisar os indicadores de performance do setor avícola no Brasil como um todo, indicadores estes de autoria da Empresa Brasileira de Pesquisa Agropecuária (Embrapa). Conforme o gráfico estabelece (Figura 2), a produção mundial de carne de frango no ano de 2017 coloca o Brasil na segunda posição dentre os países analisados, produzindo, no referido ano, 13.150 toneladas de carne de frango, só ficando atrás dos Estados Unidos, que produziram 18.696 toneladas de frango. 
Figura 2 - Gráfico da produção de carne de frango mundial em 2017

\title{
Estatísticas | Mundo | Frangos de corte
}

\author{
Carne | mil toneladas | 2017
}

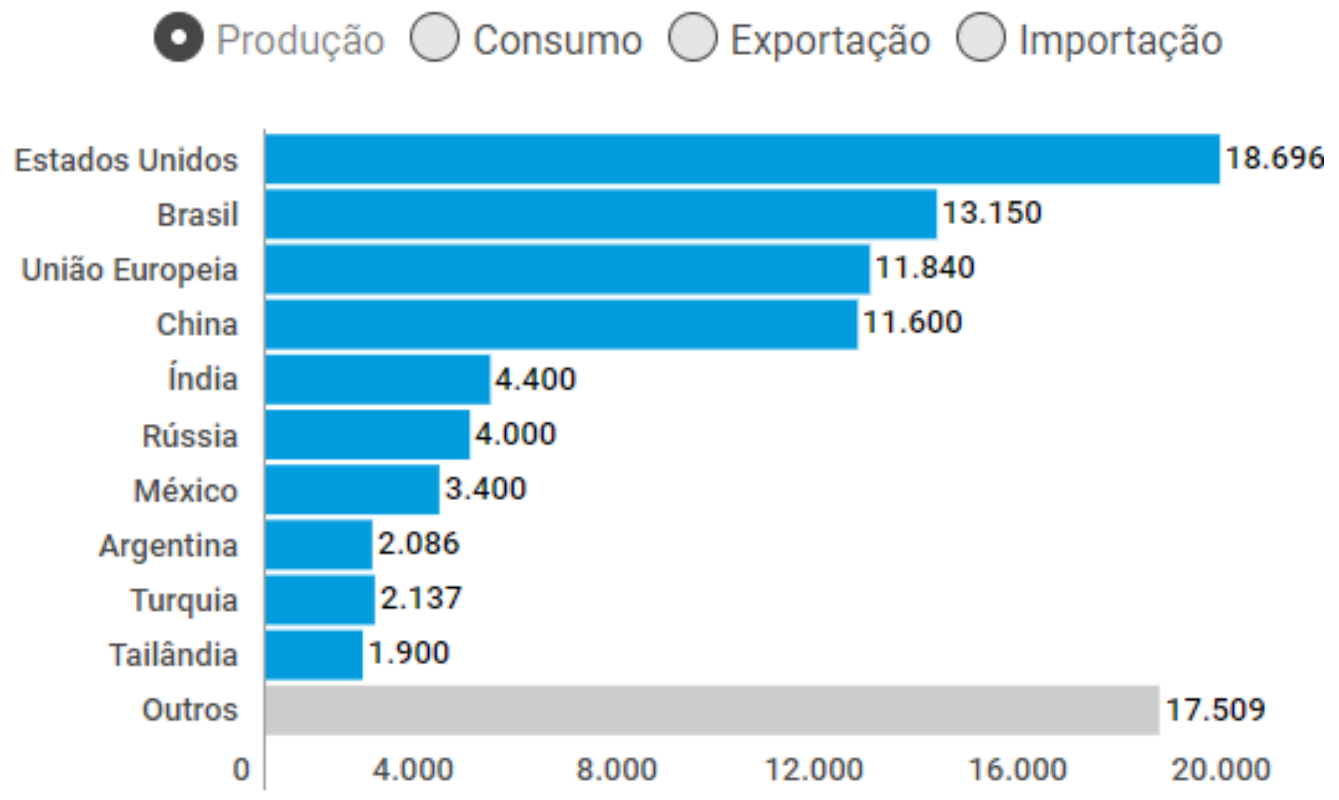

Fonte: Embrapa, 2017.

Com relação à produção nacional, a região Sul do país se destaca como a principal região ao elencar três estados (Paraná, Santa Catarina e Rio Grande do Sul) nas três primeiras posições do ranking. A Bahia aparece entre as dez primeiras colocadas, na nona posição, conforme a figura 3 . 
Agroindústria, industrialização e competitividade:

uma análise do complexo agroindustrial do Recôncavo Sul da Bahia

Gesner Brehmer de Araújo SILVA; José Raimundo de Oliveira LIMA

Figura 3- Gráfico da produção de carne de frango no Brasil em 2017

\section{Estatísticas | Brasil | Frangos de corte}

Maiores produtores e exportadores | carne | mil toneladas | 2017

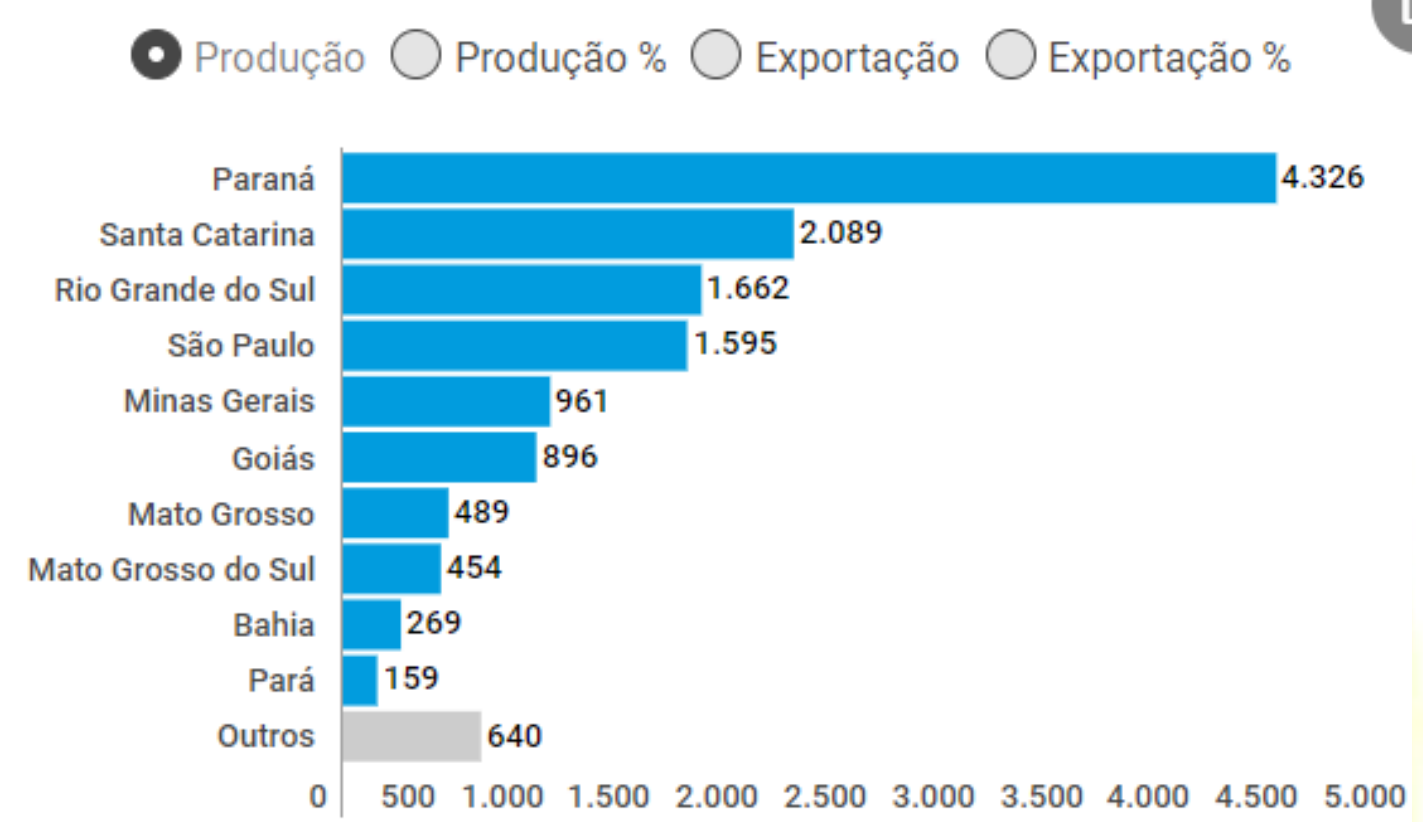

Fonte:Embrapa, 2017.

Um outro dado interessante que demonstra a pujança do setor avícola na região Nordeste é o alojamento de pintos na região. No entanto, como demonstra a tabela 1 , houve um decréscimo do número de alojamentos da Região Nordeste se considerarmos o período 2014-2018, o que pode ser entendido como uma perda de competitividade da região perante o mercado nacional e internacional.

Revista do Instituto Histórico e Geográfico do Pará (IHGP), (ISSN: 2359-0831 - online), Belém, v. 06, n. 02, p. 26-40, jul. / dez. 2019. 
Tabela 1 - Alojamento regional de pintos de corte 2014-2018

\begin{tabular}{|c|c|c|c|c|c|}
\hline \multicolumn{5}{|c|}{$\begin{array}{c}\text { Regiäo Nordeste } \\
\text { Milhos de Cabeças }\end{array}$} \\
\hline & $\mathbf{2 0 1 4}$ & $\mathbf{2 0 1 5}$ & $\mathbf{2 0 1 6}$ & $\mathbf{2 0 1 7}$ & $\mathbf{2 0 1 8}$ \\
\hline JAN & 43,9 & 42,8 & 42,8 & 42,4 & 46,9 \\
\hline FEV & 38,9 & 40,0 & 41,4 & 37,9 & 40,5 \\
\hline MAR & 40,5 & 44,3 & 44,1 & 41,0 & 40,6 \\
\hline ABR & 41,6 & 44,9 & 41,8 & 39,6 & 38,4 \\
\hline MAI & 41,6 & 43,3 & 41,2 & 42,3 & 38,8 \\
\hline JUN & 40,8 & 45,9 & 40,9 & 42,5 & 38,9 \\
\hline JUL & 44,6 & 45,3 & 41,3 & 42,2 & 39,3 \\
\hline AGO & 42,6 & 42,4 & 41,3 & 43,4 & 42,2 \\
\hline SET & 43,5 & 42,9 & 38,0 & 40,9 & 40,4 \\
\hline OUT & 45,6 & 44,6 & 41,7 & 44,4 & 42,9 \\
\hline NOV & 41,5 & 40,8 & 41,9 & 43,3 & 41,5 \\
\hline DEZ & 45,7 & 44,6 & 44,2 & 44,9 & 43,1 \\
\hline TOTAL & 511,0 & 522,1 & 500,7 & 504,8 & 493,6 \\
\hline \hline
\end{tabular}

Fonte: APINCO

De posse dessas informações,podemos concluir que, embora nos últimos anos segundo Souza (2004) -, o Nordeste e principalmente a Bahia, através do Complexo Agroindustrial do Rêconcavo Sul, tenham aumentado seu parque agroindustrial com a presença de novas indústrias, este fato não foi suficiente para fazer com que a sua participação na produção nacional aumentasse.Porém, os estudos de Carmo (2000) e Menezes revelam que o complexo agroindustrial do Recôncavo Sul apresenta desvantagens competitivas em relação às outras estruturas produtivas do Nordeste. Estas desvantagens competitivas serão apresentadas na próxima seção.

\section{DESVANTAGENS COMPETITIVAS DO COMPLEXO AGROINDUSTRIAL DO RECÔNCAVO SUL}

Para Carmo(2000) e Menezes(2001), a principal desvantagem competitiva do complexo agroindustrial do Recôncavo Sul é a não implementação do sistema de produção Revista do Instituto Histórico e Geográfico do Pará (IHHGP), (ISSN: 2359-0831 - online), Belém, vo 06, n. 02, p. 26-40, jul. / dez. 2019. 
integrado, que procura conciliar a eficiência produtiva dos pequenos agricultores junto a enorme capacidade de produção em escala e distribuição dos processadores de carne. Este processo permite que ocorra uma rápida transferência de tecnologia entre os setores via oferta de serviços essenciais ao complexo - assistência técnica, por exemplo - os quais, por consequência, irão aumentar a produtividade da região.

No Complexo Agroindustrial do Recôncavo Sul predomina o sistema de produção independente em detrimento do sistema de produção integrado, o que constitui um ponto fraco para a formação de um cluster regional.Carmo(2000), ao realizar sua pesquisa, concluiu - a partir dos indicadores econômicos e financeiros para o sistema de produção independente e $\quad 0$ sistema de produção integrada -, que o sistema integrado de produção é mais eficiente, pois no sistema de produção independente, os animais são abatidos com idade de 52 dias, com peso de 2,48 kg, com conversão alimentar de 2,11 ; enquanto que, no sistema integrado, a idade de abate cai para 49 dias, com um peso de abate médio de $2,56 \quad \mathrm{~kg}$ e uma conversão alimentar de 2,05. Outra desvantagem do complexo agroindustrial em relação aos seus concorrentes diz respeito ao sistema de inspeção sanitária. Quanto a estas considerações, Souza (2004) diz:

Enquanto nas regiões concorrentes, os governos locais já implantaram o sistema de inspeção, o que mostra a preocupação do setor público em garantir a sanidade dos produtos que abastecem o mercado interno daquelas cidades e regiões, o mesmo não se observa no mais importante pólo agroindustrial avícola da Bahia. Esse pode ser apontado como outro ponto fraco da cadeia produtiva no estado, para o desenvolvimento de um cluster. (SOUZA, 2004).

Outra desvantagem a ser combatida pelo complexo do Recôncavo Sul, no que diz respeito aos seus concorrentes, são os conjuntos de suporte fundamental: logística de transporte, sistema educacional e sistema financiamento, através dos centros de pesquisa e universidades. Ainda que nos últimos anos, investimentos por parte do governo estadual se empenhem em promover a revitalização das estradas que cortam o recôncavo Sul - e houve significativo avanço em termos educacionais com a implantação de universidades públicas e faculdades privadas -, é necessário promover uma maior integração entre o setor produtivo e 
o setor acadêmico para, de fato, implementar, de forma permanente, a formação de clusters no complexo agroindustrial

\section{CONSIDERAÇÕES FINAIS}

Através dos resultados obtidos neste artigo, vimos que o complexo agroindustrial do Recôncavo Sul, embora altamente importante para a atividade avícola da Bahia, precisa de um planejamento estratégico voltado para o desenvolvimento de suas potencialidades físicas, logísticas e intelectuais. É papel tanto do governo do Estado quanto dos empresários dos empreendimentos ali instalados desenvolverem este plano que conduza o complexo a estabelecer a condição de um cluster agroindustrial.

Nesta conjuntura, é preciso pensar em como os pontos fortes, tanto em termos locacionais quanto em termos econômicos, podem formar um elo com as oportunidades da conjuntura econômica para que os indicadores possam privilegiar os setores mais necessitados e importantes pra o suporte deste processo, como o investimento em logística de transporte, serviço de telecomunicações e sistema educacional. Estes investimentos irão conduzir as empresas, instaladas no complexo agroindustrial, a se concentrarem em potencializar seus pontos fortes e minimizar os custos e pontos fracos.

Além disto, em face da conjuntura internacional cada vez mais complicada e incerta, as oportunidades de promover o desenvolvimento do complexo agroindustrial, via mercado interno, não podem ser desprezadas. Todavia, essas oportunidades só serão possíveis se o complexo contornar ou superar suas dificuldades competitivas.

\section{REFERÊNCIAS BIBLIOGRÁFICAS}

ABA - ASSOCIAÇÃO BAIANA DE AVICULTURA. Relatórios estatísticos. Conceição de Feira, 2003.

ALENCAR, Edgar; GRANDI, Daniele Silva; ANDRADE, Débora Mesquita; ANDRADE, Márcia Pereira. COMPLEXOS AGROINDUSTRIAIS, COOPERATIVAS E GESTÃO. 2011.

APINCO-Fundação APINCO de Ciências e Tecnologias Avicolas. Relatórios estatísticos.Acesso em Fev 2019. 
ARAUJO, NB; WEDEKIN, I; PINAZZA, L. A Complexo Agroindustrial - o "Agribusiness Brasileiro", Agroceres, São Paulo, 1990, 238 p

CARMO, R.B.A. Viabilidade econômica da avicultura de corte na microregião de Feira de Santana. 2000. Dissertação (Mestrado) - Universidade Federal da Bahia, Cruz das Almas.

CAVALCANTI, Luiz Ricardo. Maturidade Tecnológica e Intensidade em Pesquisa e Desenvolvimento: o caso da indústria petroquímica no Brasil. Salvador: FIEB, 2008

COSTA, T. V. A. M. Integração regional e seus efeitos sobre as exportações brasileiras de carne avícola. 1999. Dissertação (Mestrado em Economia Rural) - Faculdade de Ciências Econômicas, Universidade Federal do Rio Grande do Sul, Porto Alegre, 1999.

DELGADO, Guilherme Costa. Capital financeiro e agricultura no Brasil: 1965-1985. Sao Paulo: ICONE, 1985.

EMBRAPA (Empresa Brasileira de Pesquisa Agropecuária).Estátisticas-Frango de Corte.Acesso Fev 2019.

GUERRA, Oswaldo; TEIXEIRA, Francisco. Estratégias para o desenvolvimento da indústria na Região Metropolitana de Salvador. In: AVENA, Armando (Org.). Bahia Século XXI. Salvador: Seplantec, Superintendência de Planejamento Estratégico, p. 147-204, 2000.

GUERRA, Oswaldo; GONZALES, Paulo. Novas Mudanças Estruturais na Economia Baiana: mito ou realidade. Fortaleza: Revista Econômica do Nordeste, v. 32, n. 3, p. 308-321, jul-set. 2001.

GUERRA, Oswaldo; TEIXEIRA, Francisco. 50 Anos da Industrialização Baiana: do enigma a uma dinâmica exógena e espasmódica. Bahia: Análise\&Dados. Ano $10 \mathrm{n}^{\circ}$ 01, Salvador: Superintendência de Estudos Econômicos e Sociais da Bahia, v. 10, n. 1, jul. 2002, p. 87-98.

GONÇALVES,Jackson Eduardo. CONTEXTUALIZAÇÃO DO COMPLEXO AGROINDUSTRIAL BRASILEIRO. SOBER.2011.

KAGEYMA, A. (Coord.). O novo padrão agrícola brasileiro: do complexo rural aos complexos agroindustriais. Campinas: Unicamp/IE, 1987.

KAGEYAMA, A. et al. O novo padrão agrícola brasileiro: do complexo rural aos complexos agroindustriais. In. DELGADO, G.; GASQUES, J.G.; VILLA VERDE, C.M. Agricultura e políticas públicas. Brasília, IPEA, 1990. p. 113- 223.

LAMOUNIER, B. Determinantes políticos da política agrícola. Brasília: IPEA, 1994. 58 p. 
MARAFON, G. J. Constituição do Complexo Agroindustrial e a Modernização da Agricultura: O Caso do Município de Marau-RS. Rio Claro, IGCE / UNESP 1988. 123 p. (Dissertação de Mestrado).2000.

MASCARENHAS, Albérico Machado. A atividade de fomento na Bahia: uma retrospectiva dos últimos 50 anos. In:.CONSELHO REGIONAL DE ECONOMIA-BA. Reflexões de economistas baianos. Salvador: CORECON, 2001. p. 62-77.

MENEZES, R. N. S. Competitividade do frango produzido nos estados da Bahia e Minas Gerais. Cruz das Almas, 2001. Dissertação (MS) - Universidade Federal da Bahia, Salvador.

MÜLER, G. O complexo agroindustrial brasileiro. Belo Horizonte: UFMG/CEDEPLAR. 1982.

PESSOTI, Gustavo Casseb. Um Estudo da Política Industrial na Bahia entre 1950 e 2005. Dissertação de Mestrado. Salvador: PPDRU/ UNIFACS, 2008, 215p

PESSOTI, Bruno Casseb; PESSOTI, Gustavo Casseb. A economia baiana e o desenvolvimento industrial: Uma análise do período 1978-2010.RDE- Revista de Desenvolvimento Econômico. Salvador.2010.

SILVA, J.G. A nova dinâmica da agricultura brasileira. Campinas: UNICAMP/IE, 1996.

SOUZA,Warli Anjos de . COMPETITIVIDADE DA CADEIA AGROINDUSTRIAL DE FRANGO DE CORTE DO RECÔNCAVO SUL DA BAHIA. 2004.

Trabalho enviado em: 19/07/2019

Trabalho aceito em: 15/12/2019 